\title{
AN ADAPTIVE THERMAL COMFORT MODEL FOR HOT HUMID SOUTH- EAST ASIA
}

Anh Tuan Nguyen*, Manoj Kumar Singh, Sigrid Reiter

Local Environment Management and Analysis (LEMA), University of Liège, Belgium

*Corresponding author: natuan@ud.edu.vn; anhtuan.nguyen@doct.ulg.ac.be

\begin{abstract}
The present paper presents a full procedure to develop an adaptive comfort model for South-East Asia. Meta-analysis on large number of observations from field surveys which were conducted in this region was employed. Standardization and bias control of the database were fully reported. Statistical tests of significance and weighted regression method applied in the analyses strengthened the reliability of the findings. This paper found a great influence of 'Griffiths constant' on the establishment of adaptive comfort equation and proposed an appropriate value. The adaptive comfort model generated is applicable to naturally ventilated building under hot and humid conditions of South-East Asia. The mean neutral comfort temperature (operative temperature, effective temperature, standard effective temperature) in naturally ventilated and air-conditioned building was compared and the differences have been discussed. The similar neutral standard effective temperature in both naturally ventilated and air-conditioned building proposes a new idea to implement SET* into building simulation tools to assess thermal comfort without the attention of building classification.

Through the analysis, the effectiveness of behavioral adaptive actions on occupant's thermal perception has been argued. The extended PMV-PPD model for hot humid conditions was examined and its applicability was recommended. Other comfort related issues, the differences and similarities between various adaptive comfort models were also addressed.
\end{abstract}

Keywords: naturally ventilated building, meta-analysis, adaptive thermal comfort, South-East Asia, hot humid climate

\section{Introduction}

Taking into account thermal comfort is very important for architects and engineers to ensure comfort and health of occupant in the building. A good estimation of built environment not only offers comfortable thermal sensation to occupants, but it also determines the amount of energy that will be consumed by cooling and heating systems of the building. In the context of climate change and global warming, the inclusion of adaptive thermal comfort concept in the thermal comfort standards which allows adopting new energy efficiency strategies and consistently meeting the requirement of sustainable development makes it more relevant to present context.

In the early 1970s, the 'steady state' thermal comfort theory proposed by Fanger [1] has become the foundation of international thermal comfort standards such as ISO 7730 [2] and ASHRAE 55 [3]. This model combines six conventional indexes (air temperature, mean radiant temperature, water vapor pressure, air velocity, occupant's clothing insulation and metabolic rate) to predict occupant's thermal sensation in a controlled climate chamber or air-conditioned (AC) environment. However, many field studies have shown that this model has failed to predict the thermal sensation of occupants living in "free running" buildings, not only in hot climates but also in temperate climates. The failure to predict the sensation happens because of the fact that the PMV model cannot take into account complex human interactions with surrounding environment by changing their behavior and slowly getting adapted by adjusting their expectations and preferences.

'Steady state' comfort theory was first challenged by Nicol and Humphreys [4] in 1972. They also put forth the concept of adaptation of occupants and explained the limitation of steady state comfort theory to conditioned built environment. So far many adaptive comfort models 
have been developed, for example adaptive model in ASHRAE 55-2004 [5] and EN15251 [6]... Detailed research [7] has also pointed out that the application of adaptive comfort standard in real building offers a huge potential in energy saving. The above saving translates to approximately $30 \%$ of the cooling load, compared to that of a fixed temperature setpoint as indicated by conventional comfort theory.

This article does not argue the validity of adaptive comfort theory since it has been continuously clarified during the last 2 decades. Instead, the article focuses on the development of an applied comfort model based on the adaptive comfort theory for hot humid South-East Asia.

Nicol [8] carried out a meta-analysis on the database of 25 comfort field surveys in hot humid climate and reported that adaptive comfort temperature in hot humid climate significantly differs from that in temperate and hot dry climate. South-East Asia commonly has hot and humid climate all year round. The majority of the population almost originates from similar cultural background. They prefer to live in naturally ventilated (NV) buildings because the socio-economic and socio-cultural preferences are optimally addressed in these buildings. Therefore, the determination of an adaptive comfort model which can be widely applied within this region is needed. This study describes the research methodology in detail, followed by the results and discussions through which an adaptive comfort model for this region is generated. Other comfort related issues, the differences and similarities between various adaptive comfort models were also addressed in subsequent sections.

\section{Research methodology}

The adaptive approach for occupant's thermal comfort relies on the analysis of the data collected during comfort surveys conducted in the field. The researchers then use statistical method to analyze the recorded data from field surveys. Since errors can rise from many sources, e.g. measuring error, data recording error or calculating error etc., a large sample is usually required for a reliable statistics. Meta- analysis [9] which combines the results of several surveys to address a set of related research hypotheses was applied in this research. The general aim of a meta-analysis is to build a more powerful adaptive comfort model through a large database collected from methodologically sound studies by removing the inconsistent data and also the inconsistency between the data collected from different comfort surveys. Although this method has both advantages and weaknesses [10,11], it has been frequently used in other thermal comfort researches related to data from field surveys [12,13, 14, 8].

The comfort surveys selected were based on the following criteria

(1) Survey locations are scattered around hot humid regions of South-East Asia (climatic boundary instead of political one);

(2) Quality of the survey and subsequently the data was ensured by final research publication;

(3) Raw data file (not only the research report or publication) created by the original researchers is available.

Table 1 summarizes basic information of 11 comfort surveys included in this research database. All observations of gathered surveys were then transferred into a meta-file in a spreadsheet for statistical analysis. Totally 5176 sets of environmental and subjective observations were included in the database (3430 records in NV building). Only 402 observations of this database will be then eliminated by the data standardization. Comparing with other surveys (e.g. European SCATs project [13] with total 4655 records - 1449 in free running building), this amount is considered to be sufficiently large for a reliable meta-analysis.

For the purpose of statistical analysis of data in this study, the responses of all subjects of longitudinal surveys (few subjects, sampled many times during a long period, as in case of Guangzhou and Manila) were assumed to be independent. It means that observations of longitudinal surveys were treated in the same manner as cross-sectional surveys. Since the 
earliest survey was carried out 25 years ago, we also assumed that human thermal perception and preference does not change over time.

Table 1: Summary of the field survey database for the present research

\begin{tabular}{|c|c|c|c|c|c|c|c|c|}
\hline Location & $\begin{array}{l}\text { Building } \\
\text { type }\end{array}$ & $\begin{array}{l}\text { Climate } \\
\text { type }^{1}\end{array}$ & $\begin{array}{l}\text { Year } \\
\text { of } \\
\text { survey }\end{array}$ & $\begin{array}{l}\text { ASHRAE } \\
\text { Classification } \\
{[12]}\end{array}$ & $\begin{array}{l}\text { Type of } \\
\text { survey }\end{array}$ & $\begin{array}{l}\text { Sample } \\
\text { size }\end{array}$ & $\begin{array}{l}\text { Research } \\
\text { leader }\end{array}$ & $\begin{array}{l}\text { Principle } \\
\text { publication } \\
\text { or sources }\end{array}$ \\
\hline Singapore & NV & $\begin{array}{l}\text { Wet } \\
\text { equatorial }\end{array}$ & 1987 & Class 2 & $\begin{array}{l}\text { cross- } \\
\text { sectional }\end{array}$ & 583 & $\begin{array}{l}\text { R. de } \\
\text { Dear }\end{array}$ & {$[12]$} \\
\hline Bangkok & NV & $\begin{array}{l}\text { Tropical } \\
\text { savanna }\end{array}$ & 1990 & Class 2 & $\begin{array}{l}\text { cross- } \\
\text { sectional }\end{array}$ & 391 & J.F. Busch & [12] \\
\hline $\begin{array}{l}\text { Jakarta - } \\
\text { Indonesia }\end{array}$ & NV & $\begin{array}{l}\text { Wet } \\
\text { equatorial }\end{array}$ & 1995 & Class 3 & $\begin{array}{l}\text { cross- } \\
\text { sectional }\end{array}$ & 97 & $\begin{array}{l}\text { T.H. } \\
\text { Karyono }\end{array}$ & [12] \\
\hline Singapore & NV & $\begin{array}{l}\text { Wet } \\
\text { equatorial }\end{array}$ & 2001 & Class 2 & $\begin{array}{l}\text { cross- } \\
\text { sectional }\end{array}$ & 538 & $\begin{array}{l}\text { N. H. } \\
\text { Wong }\end{array}$ & [15] \\
\hline $\begin{array}{l}\text { Jogjakarta } \\
\text { - Indonesia }\end{array}$ & NV & $\begin{array}{l}\text { Wet } \\
\text { equatorial }\end{array}$ & 2002 & Class 2 & Hybrid & 525 & H. Feriadi & {$[16]$} \\
\hline $\begin{array}{l}\text { Johor } \\
\text { Bahru - } \\
\text { Malaysia }\end{array}$ & NV & $\begin{array}{l}\text { Wet } \\
\text { equatorial }\end{array}$ & 2009 & Class 3 & $\begin{array}{l}\text { cross- } \\
\text { sectional }\end{array}$ & 375 & I. Hussein & [17] \\
\hline $\begin{array}{l}\text { Guangzhou } \\
\text { - China }\end{array}$ & NV & $\begin{array}{l}\text { Tropical } \\
\text { savanna }\end{array}$ & $\begin{array}{l}2009- \\
2010\end{array}$ & Class 1 & Longitudinal & 921 & Y. Zhang & [18] \\
\hline Singapore & $\mathrm{AC}$ & $\begin{array}{l}\text { Wet } \\
\text { equatorial }\end{array}$ & 1986 & Class 2 & $\begin{array}{l}\text { cross- } \\
\text { sectional }\end{array}$ & 235 & $\begin{array}{l}\text { R. de } \\
\text { Dear }\end{array}$ & [12] \\
\hline $\begin{array}{l}\text { Bangkok - } \\
\text { Thailand }\end{array}$ & $\mathrm{AC}$ & $\begin{array}{l}\text { Tropical } \\
\text { savanna }\end{array}$ & 1990 & Class 2 & $\begin{array}{l}\text { cross- } \\
\text { sectional }\end{array}$ & 776 & J.F. Busch & [12] \\
\hline $\begin{array}{l}\text { Jakarta - } \\
\text { Indonesia }\end{array}$ & $\mathrm{AC}$ & $\begin{array}{l}\text { Wet } \\
\text { equatorial }\end{array}$ & 1995 & Class 3 & $\begin{array}{l}\text { cross- } \\
\text { sectional }\end{array}$ & 458 & $\begin{array}{l}\text { T.H. } \\
\text { Karyono }\end{array}$ & [12] \\
\hline $\begin{array}{l}\text { Manila - } \\
\text { Philippines }\end{array}$ & $\mathrm{AC}$ & $\begin{array}{l}\text { Wet } \\
\text { equatorial }\end{array}$ & $\begin{array}{l}2002- \\
2003\end{array}$ & Class 2 & Longitudinal & 277 & $\begin{array}{l}\text { M. M. } \\
\text { Andamon }\end{array}$ & [19] \\
\hline
\end{tabular}

In ASHRAE RP-884 project [12], all individual responses in the database were aggregated into the statistical unit of each building, thus the 21000 responses were able to reduce to 160 buildings. The building for which the regression analysis failed to reach statistical significance $(\mathrm{P}=0.05)$ was eliminated. This method has a small drawback that if the temperature range as well as the number of respondents in a building in question are small, the linear regression might fall far from the real model and the mean thermal sensation vote would not reflect exactly the thermal environment inside the building.

In this study, we aggregated the large quantity of building observations into half-degree $\left({ }^{\circ} \mathrm{C}\right)$ increments, attributed by its sample size. Weighted regression was then performed to obtain the relationship between the variables. As presented in the next sections, each scatter point in the graph has its own weight shown by its relative area. The purpose of using a weighted regression is to minimize the impact of outlying bins which consist of small number of observations. This method has an advantage that the temperature range of each bin is small $(0.5$ ${ }^{\circ} \mathrm{C}$ ), therefore mean thermal sensation vote closely corresponds with the thermal environment. For example, the scatter plot of Operative temperature $\left(\mathrm{T}_{\mathrm{o}}\right)$ versus Thermal sensation vote (TSV) is reduced from 3430 cases in the database to about 36 weighted bins (Figure 2). Each bin is a mean of comfort votes corresponding to a mean of half-degree $\left({ }^{\circ} \mathrm{C}\right)$ range of indoor temperature which was carefully sorted before by Excel ${ }^{\circledR}$ spreadsheet. We imposed a stringent criterion according to which only significant weighted regression $\left(\mathrm{P}<0.01\right.$, correlation $\mathrm{R}^{2}>$ $0.50)$ was accepted.

\section{Raw data standardization}

\footnotetext{
${ }^{1}$ Using a climate classification developed for the Macquarie University undergraduate teaching program in climatology
} 
Each comfort study included in the present database employed a specific method, although most of these studies on adaptive comfort basically relied on a relatively homogeneous modality. Therefore, for a meta-analysis, data normalization is essential. Most information related to research methodologies were obtained through the official publications or by exchanging e-mails with the original authors. This section reports in detail the data assimilation procedure.

\subsection{Consistency in occupants' clothing insulation and chair insulation effect}

Clothing insulation is always the most troublesome in any comfort field survey because of the great variety of subject's clothes. It can only be estimated precisely by using thermal manikin. However, even in an experiment in controlled climate chamber where clothing insulation was calculated using a sophisticated thermal manikin, the obtained insulation values varied considerably between manikins [12]. In ASHRAE database, all clothing insulation estimations of the field surveys were converted using ASHRAE 55-1992 clo estimation method. Meanwhile, our newly gathered data in South-East Asia used ISO 9920-1995 [20], ASHRAE 55-2004 and ASHRAE 55-1992 as clo estimation methods. As the database of this study consists of both sources, the consistency between these four methods must be verified. We found that all three methods are almost similar since they are based on the data from the works of McCullough [21, 22] and Olesen [23, 24]. Therefore, the clo estimation method throughout the database was considered identical. Besides, the insulation effect of the chair of $0.1-0.15$ was consistently added into the database by the original authors.

\subsection{Consistency in calculated parameters}

The calculated parameters consist of mean radiant temperature $\left(\mathrm{T}_{\mathrm{mrt}}\right)$, operative temperature $\left(\mathrm{T}_{\mathrm{o}}\right)$, new effective temperature $\left(\mathrm{ET}^{*}\right)$, standard effective temperature $\left(\mathrm{SET}^{*}\right)$, predicted mean vote (PMV) and predicted percentage dissatisfied (PPD). These parameters were carefully checked for consistency and recalculated wherever inconsistencies were detected. A PMV-PPD calculator on Spreadsheet developed by one of the authors which allows calculations of PMV-PPD in series was built on the code recommended by ISO 7730 [2]. ET* and SET* were calculated by the calculator of professor de Dear [25] (slightly different, but acceptable result was yielded, compared with that given by Wincomf ${ }^{\text {C }}$ used in RP-884 project). All operative temperatures were directly recalculated by a simple equation presented in ASHRAE 55-2004, based on mean radiant temperature and air temperatures plus air speed. Only for mean radiant temperature $\left(T_{\mathrm{mrt}}\right)$, we haven't collected enough information about measuring instrument and calculation method, therefore $\mathrm{T}_{\mathrm{mrt}}$ given by the original authors were accepted.

\subsection{Gathering means of outdoor temperature}

For each observation, outdoor environmental parameters must be recorded in order to relate to the observed neutral temperature. It is obvious that the exponentially weighted running mean outdoor temperature $\left(\mathrm{T}_{\mathrm{rm}}\right)$ used in European SCATs project [7] is the most appropriate index for this purpose. However, it requires continuous and detailed monitoring of outdoor conditions which are only available in pre-designed surveys (e.g. SCATs project). Acceptable and widely used outdoor reference index is the current mean monthly meteorological temperature which is the average of monthly mean maxima and minima. Mean monthly temperature is a suitable reference environmental parameter in hot humid climate region since the weather conditions are rather stable and the day and night temperature variation/swing over entire year is minimum. In the survey for which this value was omitted, the mean monthly temperature from published climatological data resource, e.g. [26], was assigned to each observation.

\subsection{Refining the data and bias control in meta-analysis}

Chi-squared test was applied to each regression analysis to verify whether there is a statistically significant linear relationship between two examined variables. The choice of significance threshold depends critically on sample size because equilibrium will always be 
rejected at conventional levels $(\mathrm{P}=0.05)$ with large sample sizes. Since the database of this study is very large, we decided to set a stringent threshold P-value of 0.01 for statistical significance. In this study all the surveys and the corresponding data after analysis which failed to reach statistical significance were eliminated or rejected.

According to the above criterion, 158 observations (4.6\% of the total) obtained from the survey in Johor Bahru - Malaysia in Nong Chik primary school (very young subjects - around 10 years old) were eliminated because the correlation coefficient of determination $\mathrm{R}^{2}$ of some regression analyses were too low and the relations were not statistically significant. The regression between $\mathrm{T}_{\mathrm{o}}$ and TSV gave $\mathrm{P}$-value $=0.023>0.01, \mathrm{R}^{2}=0.033$; and the regression between PMV and TSV gave P-value $=0.021>0.01, \mathrm{R}^{2}=0.034$. A possible reason for these inconsistencies is that many young subjects didn't understand the questionnaire and the requirements of the survey.

During the regression analyses related to occupant's thermal sensation vote on 7-point ASHRAE scale using scatter graphs; we found that a few responses exhibited very large bias from the scatter cloud. We consider them as survey errors which are inevitable in any field survey. They may come from measuring error, health problem of occupant or may occupant have special needs about thermal environment at that moment and data entry error. Standard Residual (SR) of each TSV was calculated and then used to detect abnormal bias as follow:

$$
\mathrm{SR}=\frac{Y_{o}-Y_{p}}{\sqrt{\sum_{i=1}^{n} \frac{\left(Y_{i}-\bar{Y}\right)^{2}}{n}}}
$$

where:

$Y_{o}$ is observed value (in this case: observed TSV by occupants)

$Y_{p}$ is predicted value (in this case PMV)

$Y_{i}$ is $i^{\text {th }}$ observed value

$\bar{Y}$ is arithmetic mean of the observed values

Observed TSV with absolute SR greater than 2 were eliminated since they exhibit large bias from the scatter cloud (for example, in a case where $\mathrm{T}_{0}=30.1, \mathrm{TSV}=3$ while PMV $=-0.91$, SR $=2.87>2$, therefore this vote should be eliminated from the analysis).

After Standard Residual analysis, 196 observations (5.7\% of the total) in NV database and 48 observations $(2.7 \%$ of the total) in AC database were eliminated. The bias percentage observed in NV buildings was about two times higher than that in AC buildings. Finally, the refined database consisted of 4774 observations ready for use.

\section{Results and discussions}

Although the purpose of this study is to define an adaptive comfort model for naturally ventilated building, other analyses based on survey data collected from AC buildings were also carefully examined. The similarities and differences between results of these two building types are important to strengthen our understanding about adaptive comfort approach. For this reason, analysis results of both $\mathrm{NV}$ and $\mathrm{AC}$ building were always presented together in the following sections.

\subsection{Distribution of indoor operative temperature and relative humidity}

The histograms of distribution of indoor operative temperature and relative humidity during all surveys are presented in Figure 1. It is notable that only the survey in Guangzhou - China in mild seasons (from October to April of the next year) had low temperature range - from $17{ }^{\circ} \mathrm{C}$ to $26^{\circ} \mathrm{C}$ and extremely low humidity (not shown in Figure 1). The result of this survey is significantly different from that of other surveys, as being discussed in the subsequent sections. In other surveys, the operative temperature range is $26^{\circ} \mathrm{C}$ to $35^{\circ} \mathrm{C}$ (mean $29.8{ }^{\circ} \mathrm{C}$ ) in $\mathrm{NV}$ buildings and $20{ }^{\circ} \mathrm{C}$ to $30{ }^{\circ} \mathrm{C}$ (mean $24.4{ }^{\circ} \mathrm{C}$ ) in $\mathrm{AC}$ buildings. Humidity in NV building is rather high (mean $71.7 \%$ ) and about $14 \%$ higher than that in $\mathrm{AC}$ building (mean $57.9 \%$ ). It can 
be seen that South-East Asia almost has hot and humid climate that may differently affects human thermal perception.
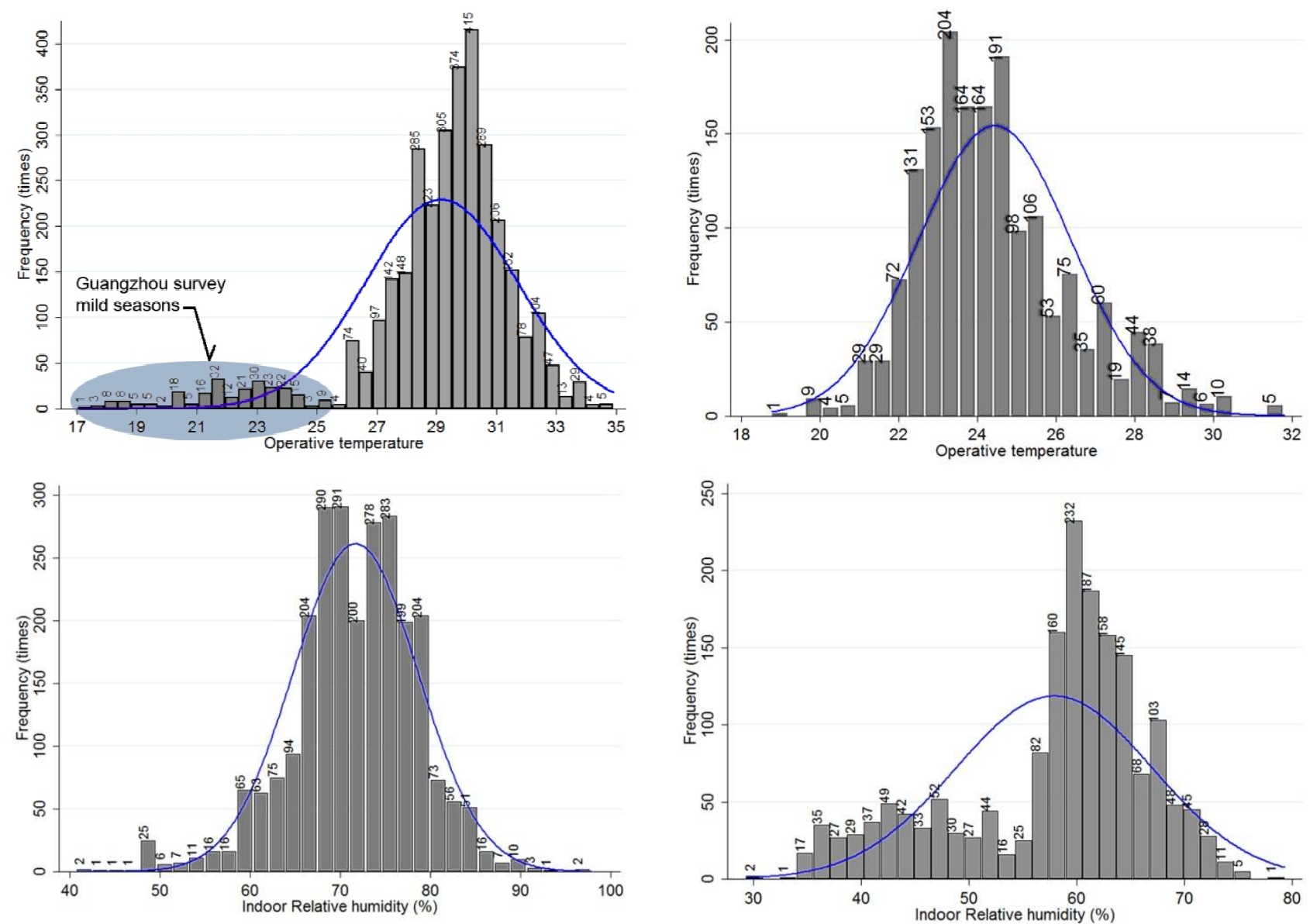

Figure 1: Distribution of indoor Operative temperature and Relative humidity in NV (left) and AC buildings (right) of all surveys

\subsection{Mean neutral temperature}

This section discusses on the observed mean neutral temperature (operative temperature, ET*$^{*}, \mathrm{SET}^{*}$ ) in both NV and AC building. Traditional methods used to derive neutral temperature from field survey data are [27]:

- Probit analysis to find a comfortable temperature at which the largest proportion of subjects is comfortable (using Bedford thermal scale).

- Regression analysis to calculate a neutral temperature at which the average person votes neutral on the 7-point thermal sensation scale. This method is employed in this study.

Weighted regression was performed as described in detail in section 2. All analysis and results presented in this section reached statistical significance $(\mathrm{P}<0.01)$.

\subsubsection{Mean neutral operative temperature}

Adaptive approach indicates that the neutral temperature is believed to change as people adapt to the changing environment by modifying their clothing, activities as well as their expectation [27] and thus the comfort temperature normally varies from month to month across the year. Neutral operative temperature calculated in this section is only the mean neutral value corresponding to an indoor temperature range.

As shown in Figure 2 (NV building - left), neutral $\mathrm{T}_{\mathrm{o}}$ in Guangzhou in mild seasons (25.5 $\left.{ }^{\circ} \mathrm{C}\right)$ is significantly lower than that $\left(27.9^{\circ} \mathrm{C}\right)$ of other surveys in warmer climates. Neutral $\mathrm{T}_{\mathrm{o}}$ in 
AC building (Figure 2 - right) is $25.8{ }^{\circ} \mathrm{C}$, similar to the results of earlier studies conducted in climate chamber [1]. Interestingly, the regression slope gradually increases when the temperature range raises (from 0.183 to 0.24 and to 0.41 ) and it peaks in NV building instead of AC building. Since the regression slope reflects occupants' sensitivity to temperature change, we argue that this regression slope does not say much about adaptation opportunities but it depends on the temperature and humidity range. It is quite obvious that at high temperature and high relative humidity (see Figure 1), adaptive actions (changing posture, opening of window, change in activities...) seem to be less effective than at lower temperature as human heat exchange with the environment would be limited. Consequently, the occupant seems to be more sensitive to thermal change. However, this phenomenon needs further investigation before drawing any conclusion.
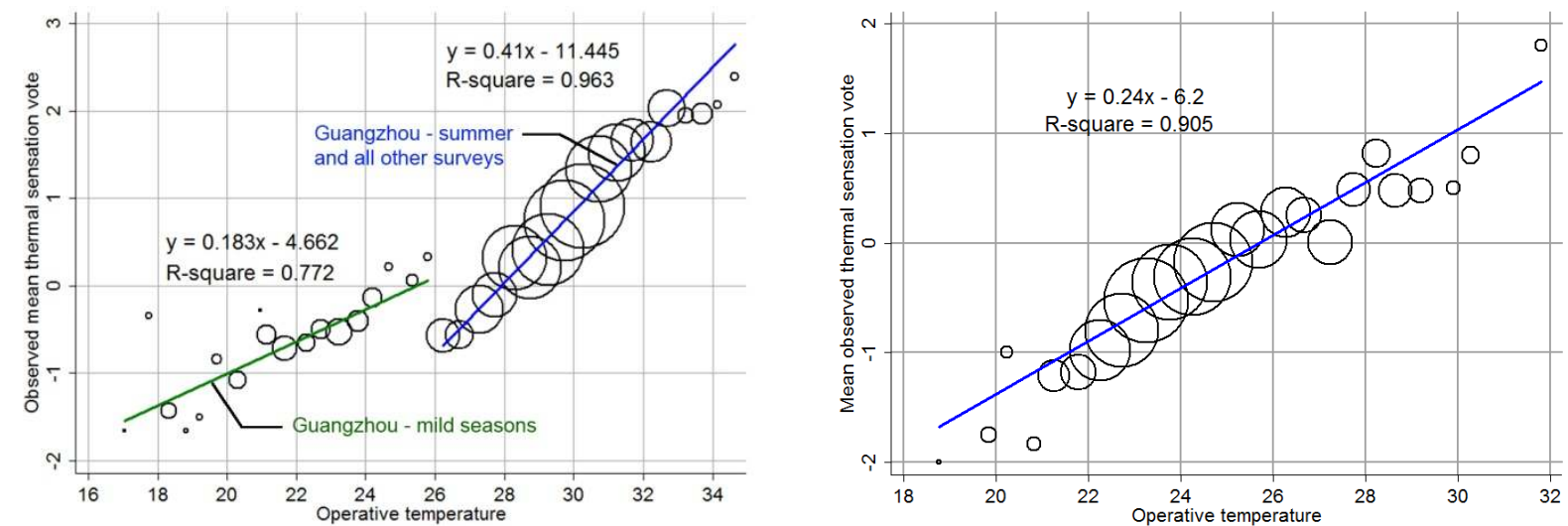

Figure 2: Weighted regression of mean operative temperature versus mean observed thermal sensation vote. In NV building (left): smallest and largest sample sizes are 1 and 430, respectively; in AC building (right): smallest and largest sample sizes are 1 and 225 , respectively.

Since the correlation coefficients $\mathrm{R}^{2}$ of these regressions are very high and the number of observation is sufficiently large, thus this analysis gives very strong evidence that neutral temperature is a "moving target" instead of a fixed prescribed temperature. Comfort temperature found in climate chamber (around $25.5^{\circ} \mathrm{C}$ ) [1] does not reflect the complex ways people interact with their surrounding environment.

\subsubsection{Mean neutral effective temperature ET*}

As shown in Figure 3, mean neutral ET* is NV and AC building are $27.1{ }^{\circ} \mathrm{C}$ and $25.9{ }^{\circ} \mathrm{C}$, respectively. The regression equations of $\mathrm{NV}$ and $\mathrm{AC}$ building were nearly similar. The difference between mean neutral $\mathrm{ET}^{*}$ of $\mathrm{NV}$ and $\mathrm{AC}$ building still existed but it was smaller than that of operative temperature. 

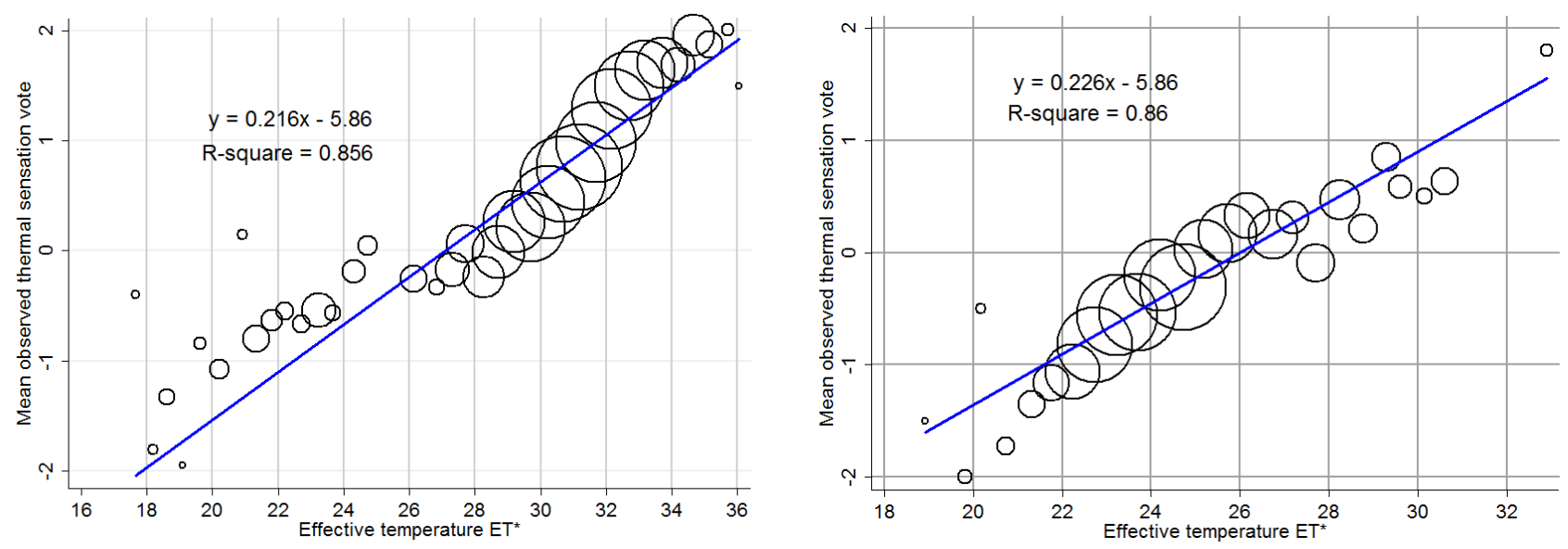

Figure 3: Weighted regression of mean effective temperature versus mean observed thermal sensation vote. In NV building (left): smallest and largest sample sizes are 2 and 298, respectively; in AC building (right): smallest and largest sample sizes are 2 and 229 , respectively.

\subsubsection{Mean neutral Standard effective temperature SET*}

Different from previous regression in Figure 2 and 3, Figure 4 shows that the regression equations of SET* versus TSV in NV and AC buildings are almost identical. Very high observed correlations $\left(\mathrm{R}^{2}\right)$ mean that there are strong relations between SET and TSV. So the outcome, neutral temperature, calculated based on this analysis is more accurate. This analysis indicates that mean neutral SET* in both NV and AC buildings are about $25.5-25.7^{\circ} \mathrm{SET}^{*}$. This observed neutral temperature is very close to the neutral temperature found by Fanger [1] in his climate chamber experiment in Denmark and by his comfort equation. So it can be concluded that neutral SET* in AC and NV building are not different although the respective neutral operative temperatures deviate considerably, from each other.

Table 2: Mean observed neutral temperature under hot and humid conditions of SouthEast Asia

\begin{tabular}{|l|l|l|l|l|l|l|l|l|l|l|}
\hline \multirow{2}{*}{$\begin{array}{l}\text { Building } \\
\text { type }\end{array}$} & \multicolumn{3}{|c|}{ Operative temperature } & \multicolumn{3}{|c|}{ Effective temperature } & \multicolumn{3}{|c|}{ Standard effective temperature } \\
\cline { 2 - 10 } & $\begin{array}{l}\text { Mean } \\
\text { neutral } \mathrm{T}_{\mathrm{o}}\end{array}$ & $\mathrm{R}^{2}$ & RMSE** & $\begin{array}{l}\text { Mean neutral } \\
\text { ET }\end{array}$ & $\mathrm{R}^{2}$ & RMSE & \multicolumn{2}{l}{$\begin{array}{l}\text { Mean neutral } \\
\text { SET }\end{array}$} & $\mathrm{R}^{2}$ & RMSE \\
\hline $\begin{array}{l}\mathrm{NV} \\
\text { building }\end{array}$ & $27.9^{*}$ & 0.963 & 0.102 & 27.1 & 0.856 & 0.225 & 25.5 & 0.972 & 0.083 \\
\hline $\begin{array}{l}\text { AC } \\
\text { building }\end{array}$ & 25.8 & 0.905 & 0.129 & 25.9 & 0.860 & 0.144 & 25.7 & 0.860 & 0.096 \\
\hline
\end{tabular}

* Not take into account Guangzhou survey in mild seasons

** Root mean square error between actual TSV and predicted TSV by the regression equations in Figure 2, 3 and 4

Table 2 summarizes all mean neutral temperature observed from the above analyses. It can be seen that under hot and humid conditions, the majority of occupant feels comfortable when operative temperature is about $28^{\circ} \mathrm{C}$ and this value is about $2{ }^{\circ} \mathrm{C}$ higher than that of $\mathrm{AC}$ building. This difference is mainly attributed to three adaptive actions of occupants: controlling window, varying activity levels and changing clothes (behavioral adaptation). When SET*, which takes all these adaptive actions into account and converts them into 'standard condition', was used, the difference of neutral SET* between NV and AC building becomes minimum. SET $^{*}$ is a sub-set of ET* and is defined as equivalent temperature under standardized conditions (namely, pressure at sea level with $50 \% \mathrm{RH}$, still air at 0.1 to $0.15 \mathrm{~m} / \mathrm{s}$ and standard clothing for a given activity) [28]. SET* gives a rational basis for measuring the equivalence of any 
combination of environmental factors, clothing and metabolic rate and thus SET* strongly correlates to occupant's thermal perception. The nearly similar neutral SET*s in both NV and AC building have revealed that the role of expectation (psychological adaptation) and acclimatization (physiological adaptation) were very vague and human thermal adaptation mainly relies on behavioral actions. This result also proposes a new idea to implement SET* into building simulation tools to assess thermal comfort in buildings without the attention of building classification - AC or NV. However, a specific thermal comfort experiment is needed to reconfirm the similarity of neutral SET* in AC and NV buildings.
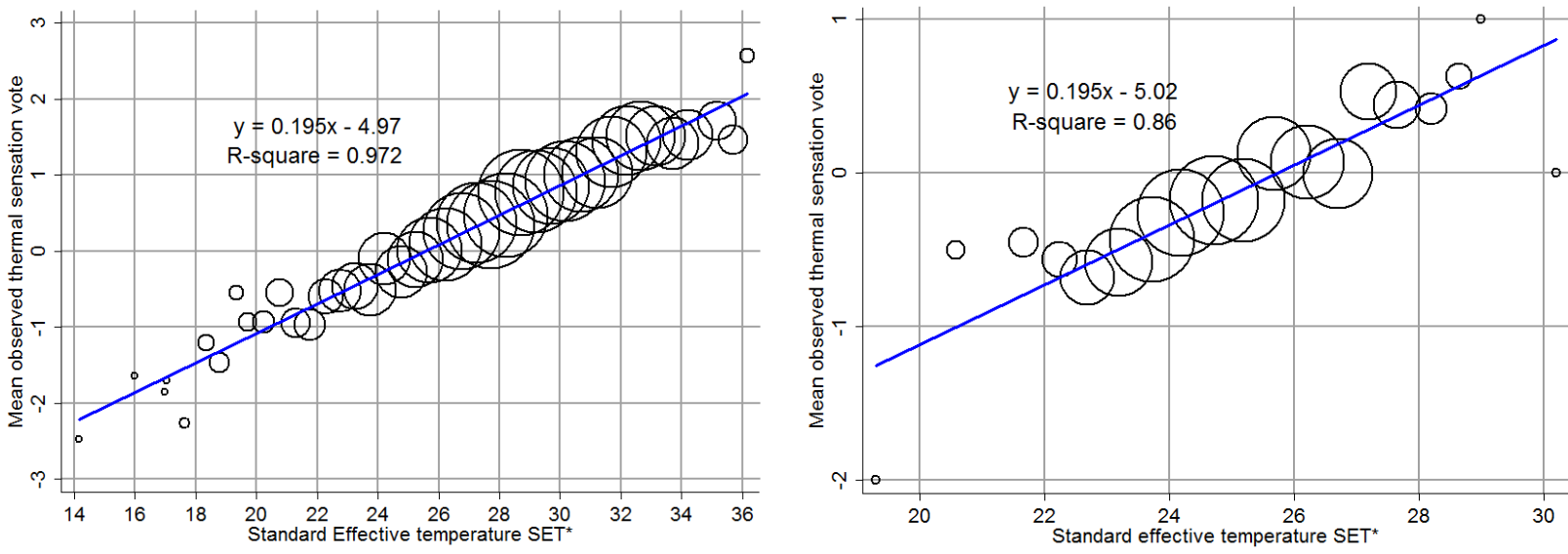

Figure 4: Weighted regression of mean standard effective temperature versus mean observed thermal sensation vote. In NV building (left): smallest and largest sample sizes are 1 and 118, respectively; in AC building (right): smallest and largest sample sizes are 1 and 93, respectively.

\subsection{An Adaptive thermal comfort model for South-East Asia}

\subsubsection{Sensitivity analysis and the choice of "Griffiths constant"}

Adaptive comfort model relates occupant's comfort temperature with outdoor weather conditions based on an assumption of adaptive approach: if a change occurs such as to produce discomfort, people react in ways which tend to restore their comfort [29]. Traditional method to build this model is linear regression in which mean comfort temperature of a group of subjects (or comfort temperature of each individual subject) is plotted versus an outdoor environmental variable, e.g mean monthly outdoor temperature. Griffiths [30] proposed a single standard value - namely Griffiths constant $G_{c o n s}$ - to predict comfort temperature $T_{\text {comf }}$ from mean or individual thermal sensation vote $T S V$ and global temperature $T_{g}$ using the equation defined as:

$$
T_{\text {comf }}=T_{g}-T S V / G_{\text {cons }}
$$
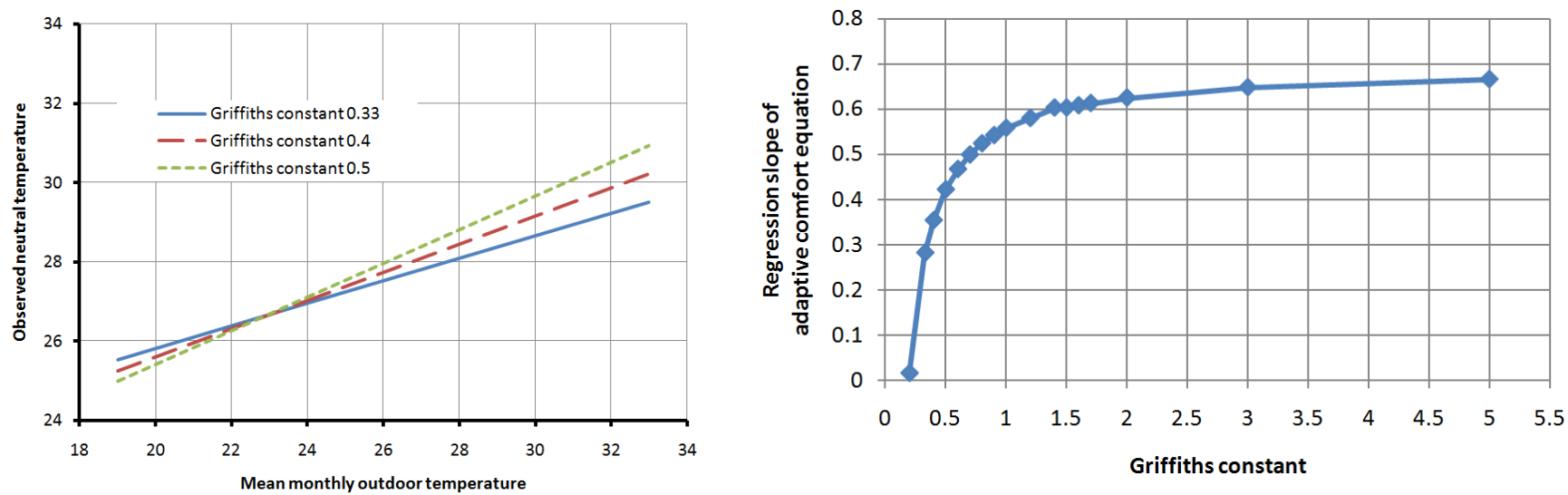
Figure 5: Sensitivity of resulted adaptive comfort model with different 'Griffiths constants'(left) and the relationship between Griffiths constant and regression slope of adaptive comfort equation (right)

If TSV is equal zero, comfort temperature is equal to global temperature. The equation (2) indicates that individual comfort temperature is rather sensitive with the change of 'Griffiths constant'. Using the database of this study, Figure 5 (left) graphically shows the sensitivity of adaptive comfort models derived from the present database if different Griffiths constants are applied. At $30^{\circ} \mathrm{C}$, if Griffiths constants chosen are 0.33 and 0.5 , resulted comfort models will produce a difference of $2.5^{\circ} \mathrm{C}$ in corresponding mean monthly outdoor temperature. Figure 5 (right) indicates that the regression slope of adaptive comfort model is very sensitive within the range of Griffiths constant from 0.2 to 0.6. Therefore, the choice of Griffiths constant plays an important role in the derived adaptive model and must be made with care.

Griffiths [30] proposed a constant of 0.33 for use in adaptive comfort study. de Dear and Brager extensively examined the ASHRAE RP-884 database to choose a 'Griffiths constant'. Based on these analyses, they proposed an appropriate 'Griffiths constant' for the relationship between thermal sensation vote and global temperature at 0.5[31]. Nicol and Humphreys [27] examined the correlation $\mathrm{R}^{2}$ of the linear regression between running mean temperature and observed comfort temperature with Griffiths constant at 0.4 and 0.5 . They finally chose the value 0.5 for the SCATs project because it gave slightly higher correlation.

We examined the correlation coefficient $\mathrm{R}^{2}$ of the adaptive comfort equation using the present database. The result is presented in Table 3 and Figure 6. Meta-analysis of different surveys conducted during a very long period consists of many input uncertainties and may produces inconsistencies among surveys. Consequently, low coefficients of correlation $\mathrm{R}^{2}$ could be observed (lower than 0.7). As shown in the next sections, weighted regression method reduced effects of bias observations by aggregating them into half-degree increments. Hence acceptable $\mathrm{R}^{2}$ of all linear regressions were achieved and the scatter plots showed trends more clearly. It was observed that the higher Griffiths constant applied, the higher correlation yielded. This directly proportional relation is quite obvious because of the direct relationship among TSV, $\mathrm{T}_{\text {comf }}, \mathrm{T}_{\mathrm{o}}, \mathrm{T}_{\text {out }}$ and $\mathrm{G}_{\text {cons. }}$. These analyses revealed that the correlation coefficient $\mathrm{R}^{2}$ cannot be the criteria for the selection of Griffiths constant. Another solution is therefore needed.

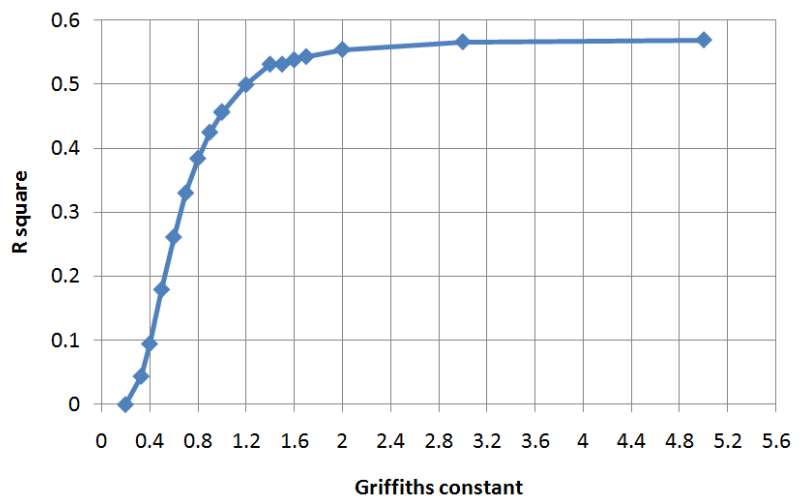

Figure 6: Relationship between Griffiths constant and correlation coefficient of adaptive comfort equation

Table 3: The role of Griffiths constant in the establishment of adaptive comfort equation and its correlation $\mathrm{R}^{2}$

\begin{tabular}{|l|l|l|l|l|l|}
\hline $\begin{array}{l}\text { 'Griffiths } \\
\text { constant' }\end{array}$ & $\begin{array}{l}\text { Adaptive comfort } \\
\text { equation }\end{array}$ & $\begin{array}{l}\mathrm{R}^{2}-\text { direct } \\
\text { regression }\end{array}$ & $\begin{array}{l}\text { 'Griffiths } \\
\text { constant' }\end{array}$ & $\begin{array}{l}\text { Adaptive comfort } \\
\text { equation }\end{array}$ & $\begin{array}{l}\mathrm{R}^{2}-\text { direct } \\
\text { regression }\end{array}$ \\
\hline
\end{tabular}




\begin{tabular}{|l|l|l|l|l|l|}
\hline 0.2 & $\mathrm{~T}_{\text {comf }}=0.017 \mathrm{~T}_{\text {out }}+26.20$ & 0.00006 & 1.2 & $\mathrm{~T}_{\text {comf }}=0.581 \mathrm{~T}_{\text {out }}+13.36$ & 0.499 \\
\hline $0.33^{*}$ & $\mathrm{~T}_{\text {comf }}=0.284 \mathrm{~T}_{\text {out }}+20.14$ & 0.0443 & 1.4 & $\mathrm{~T}_{\text {comf }}=0.604 \mathrm{~T}_{\text {out }}+12.85$ & 0.531 \\
\hline 0.4 & $\mathrm{~T}_{\text {comf }}=0.355 \mathrm{~T}_{\text {out }}+18.50$ & 0.095 & 1.5 & $\mathrm{~T}_{\text {comf }}=0.607 \mathrm{~T}_{\text {out }}+12.85$ & 0.534 \\
\hline $0.5 * *$ & $\mathrm{~T}_{\text {comf }}=0.423 \mathrm{~T}_{\text {out }}+16.96$ & 0.180 & 1.6 & $\mathrm{~T}_{\text {comf }}=0.609 \mathrm{~T}_{\text {out }}+12.72$ & 0.538 \\
\hline 0.6 & $\mathrm{~T}_{\text {comf }}=0.468 \mathrm{~T}_{\text {out }}+15.93$ & 0.262 & 1.7 & $\mathrm{~T}_{\text {comf }}=0.614 \mathrm{~T}_{\text {out }}+12.61$ & 0.543 \\
\hline 0.7 & $\mathrm{~T}_{\text {comf }}=0.500 \mathrm{~T}_{\text {out }}+15.20$ & 0.331 & 2 & $\mathrm{~T}_{\text {comf }}=0.626 \mathrm{~T}_{\text {out }}+12.33$ & 0.554 \\
\hline 0.8 & $\mathrm{~T}_{\text {comf }}=0.525 \mathrm{~T}_{\text {out }}+14.65$ & 0.385 & 3 & $\mathrm{~T}_{\text {comf }}=0.649 \mathrm{~T}_{\text {out }}+11.82$ & 0.566 \\
\hline 0.9 & $\mathrm{~T}_{\text {comf }}=0.543 \mathrm{~T}_{\text {out }}+14.22$ & 0.426 & 5 & $\mathrm{~T}_{\text {comf }}=0.667 \mathrm{~T}_{\text {out }}+11.41$ & 0.569 \\
\hline 1 & $\mathrm{~T}_{\text {comf }}=0.559 \mathrm{~T}_{\text {out }}+13.88$ & 0.457 & & & \\
\hline
\end{tabular}

* This value was proposed by Griffiths

** This value was used in ASHRAE RP-884 and European SCATs project

We tried to predict the regression slope (Griffiths constant) from standard deviation of indoor operative temperature (see Figure 7), as done previously by Humphreys et al. [32]. However, within our database, this correlation was very weak $\left(\mathrm{R}^{2}=0.25\right)$ and this low correlation failed to reach statistical significance using a chi-square test $(P=0.0792>0.05)$. It means that an appropriate Griffiths constant should be chosen regardless of the standard deviation of indoor operative temperature.

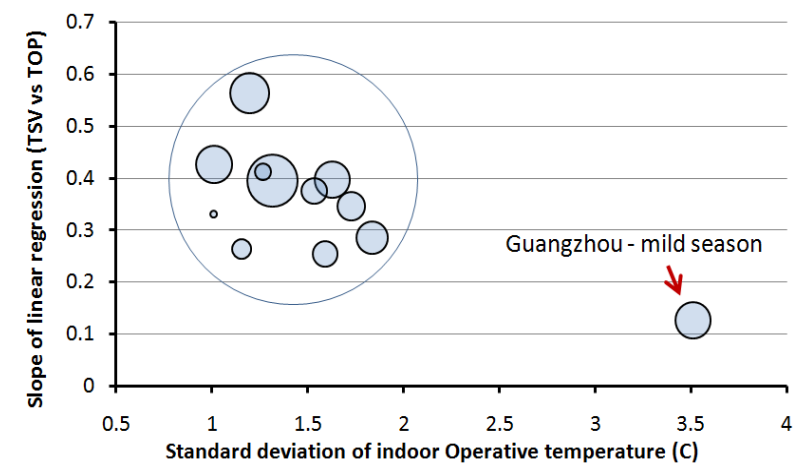

Figure 7: Slope of the regression in relation to the standard deviation of indoor operative temperature. Each point represents the slope of linear regression of a survey in a country, in NV or AC buildings, except the survey in Guangzhou which was divided into two surveys: hot season and mild seasons (Smallest and largest sample sizes are 97 and 762, respectively)

Finally, we decided to use the weighted mean of the regression coefficients of these surveys (the number of respondent was also taken into account as weighing factor). Weighted mean value of all regression coefficients was 0.384 (we excluded the extreme bias point of Guangzhou in mild seasons). This value is used to derive a comfort temperature from each thermal sensation vote and indoor operative temperature. Since this value was derived from a large number of surveys, we also recommend this value for other similar adaptive comfort study in hot humid climate.

\subsubsection{Adaptive comfort equation}

Figure 8 (left) presents the adaptive comfort equation developed for NV building. The correlation $\mathrm{R}^{2}$ of this equation reaches 0.52 . As being analyzed above, a raising Griffiths constant would raise the $\mathrm{R}^{2}$. If we used the Griffiths constant of 0.5 as being used by ASHRAE in the standard 55-2004, we would achieve the correlation $\mathrm{R}^{2}$ of 0.698 which is almost equal to that (0.7) of the standard 55-2004 [33]. The comfort equation of EN15251 had much higher correlation since it only used the data of SCATs project which was specially designed for this standard. The $95 \%$ confidence intervals indicates that this adaptive comfort equation is highly reliable in the range of mean monthly outdoor temperature from 24 to $30{ }^{\circ} \mathrm{C}$ (It would be $95 \%$ 
confident that the predicted comfort temperature has an accuracy of $\pm 0.5^{\circ} \mathrm{C}$ ). This also reveals that the model needs further investigation when mean monthly outdoor temperature drops below $24{ }^{\circ} \mathrm{C}$ or exceeds $30{ }^{\circ} \mathrm{C}$.
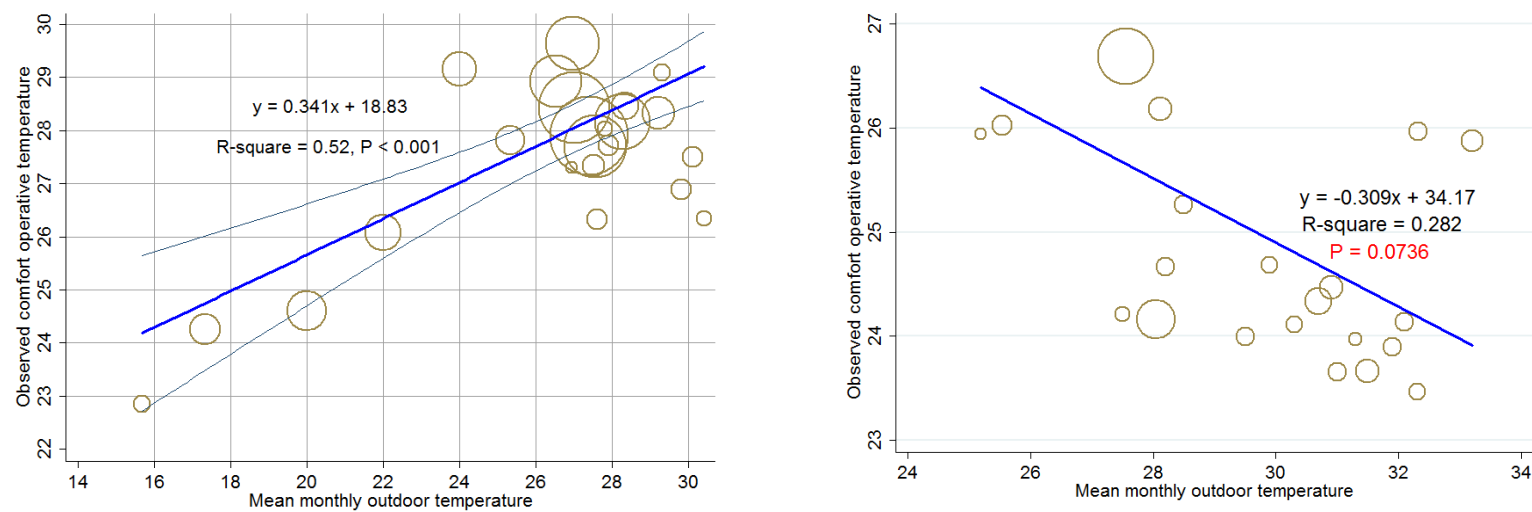

Figure 8: Predicted comfort temperature for NV building (left - largest bubble size: 569, smallest bubble size: 14) and AC building (right - largest bubble size: 458, smallest bubble size: 21) with Griffiths constant 0.384. Each bubble represents mean vote corresponding to a mean monthly temperature, each bin "data point" was weighted according to the number of respondents it represents. $95 \%$ confidence intervals of the regression line were also shown.

The comfort equation for NV building achieved from this analysis $\left(\mathrm{T}_{\text {comf }}=0.341 \mathrm{~T}_{\mathrm{a} \text {,out }}+\right.$ $18.83)$ is slightly higher to that of ASHRAE standard 55-2004 $\left(\mathrm{T}_{\text {comf }}=0.31 \mathrm{~T}_{\mathrm{a} \text {,out }}+17.8\right)$ and much closed to EN15251 ( $\mathrm{T}_{\text {comf }}=0.33 \mathrm{~T}_{\mathrm{rm}}+18.8$; free-running building). Although the methods and independent variables related to adaptive comfort temperature were different, it resulted in similar comfort equations showing a convergent trend of adaptive comfort studies with large database.

Figure 8 (right) shows the model of predicted comfort temperature for AC building. In contrast with the case of NV building, it can be seen that $\mathrm{P}$-value in this case is $\mathrm{P}=0.0736$ ( $>$ 0.01 ), thus the correlation failed to reach statistical significance. This analysis shows that in AC building, occupant's comfort temperature is almost independent of outdoor temperature.

\subsubsection{Acceptability deviation around comfort temperature}

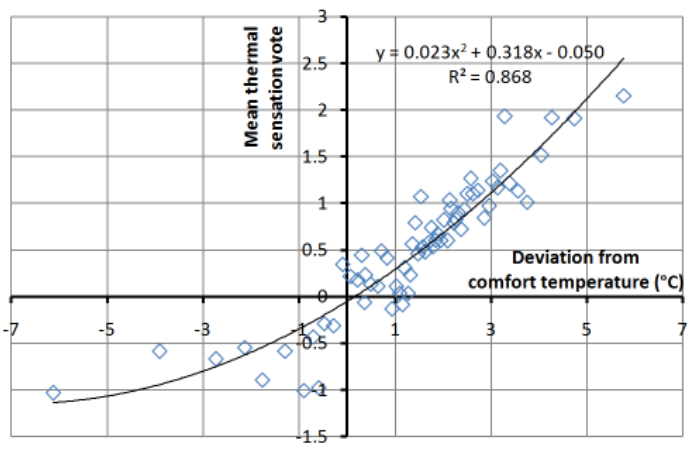

Figure 9: Change of mean thermal sensation vote corresponding to deviation from comfort temperature. Each point represents mean of 50 votes.

There is a limited interval around ideal comfort temperature given by adaptive comfort equation. This interval is called "acceptability range". Based on the result of RP-884, de Dear and Brager [33] found no climate-dependency for indoor thermal sensitivity and they stated that 
the acceptability range is unchanged across the entire range of outdoor climates. However, the result of SCATs project [7] reported that the acceptability range becomes narrower as the outdoor condition becomes warmer. To define the acceptability range, for each observation we calculated the comfort temperature as well as the deviation of indoor $T_{0}$ from comfort temperature. Then we plot the TSV versus the deviation from comfort temperature using a scatter graph. The comfort range for $80 \%$ and $90 \%$ acceptability is assumed to correlate with mean TSV of \pm 0.85 and \pm 0.5 , as Fanger PMV-PPD theory [1]. Figure 9 shows the result according to which the constant term of the regression equation is nearly zero as expected, and the correlation coefficient is fairly high. Figure 9 also reveals that subjects were less sensitive to thermal change in the cooler side of comfort temperature and vice versa. The comfort range for $80 \%$ acceptability (TSV from -0.85 to 0.85 ) is $5.7^{\circ} \mathrm{C}$ and that for $90 \%$ acceptability (TSV from -0.5 to 0.5 ) is $3.2^{\circ} \mathrm{C}$. These values are slightly lower than other standard (e.g. ASHRAE 55, EN 15251), indicating that people in South-East Asia are slightly more sensitive to temperature change. As discussed in section 4.2.1, high temperature range and relative humidity during the surveys may limit the efficiency of adaptive actions and narrowed the comfort range, consequently.

\subsection{Other comfort-related issues}

\subsubsection{PMV and TSV, expectancy factor}

Steady-state thermal comfort theory developed by Fanger [1] proposes the use of PMVPPD model to predict mean thermal sensation vote of a group of occupants. This theory was widely accepted and incorporated into some international standards. However, its applicability for occupants living in NV building in warm climate has been argued and proven inaccurate because it does not take into account of human adaptations and expectation. Fanger and Tøftum [34] proposed some corrections to make the PMV-PPD model applicable in non-air-conditioned buildings in warm climate. Their corrections adjust subject's metabolic rates by a reduction of $6.7 \%$ for every scale unit of PMV above neutral. Corrected PMV value is recalculated by using this reduced metabolic rate. Corrected PMV value is believed capable to predict occupants' thermal sensation in warm climate if it is multiplied by an appropriate expectancy factor $e$ ( $e$ varies from 0.5 to 1 - depending on the climate and popularity of air-conditioned building).

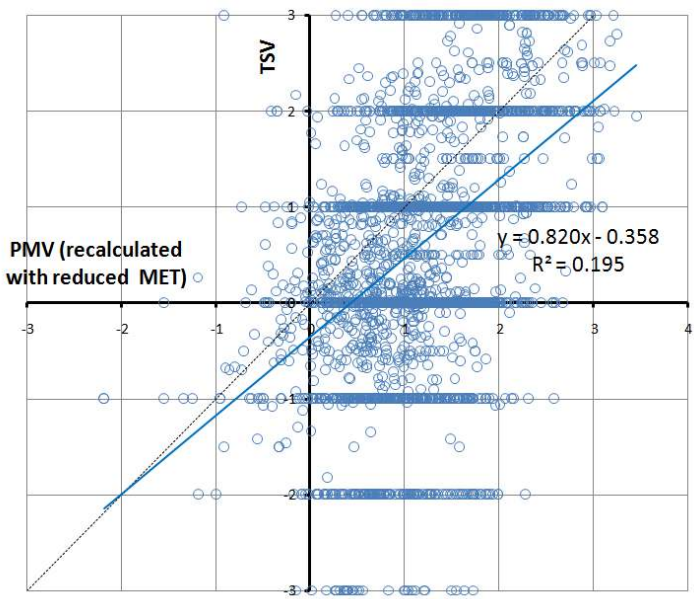

Figure 10: Corrected PMV versus thermal sensation vote in warm climate

The corrected PMV and its applicability were examined in the present study. Figure 10 shows the linear regression analysis of corrected PMV and actual thermal sensation vote (TSV). In this analysis, 2708 observations of class I and class II surveys with $\mathrm{T}_{\mathrm{o}}$ greater than $26^{\circ} \mathrm{C}$ were included (these observations include all required variables allowing to recalculate PMV index). The achieved regression equation $\left(\mathrm{R}^{2}=0.195\right)$ is: 


$$
T S V=0.82 P M V-0.358 \quad(3)
$$

It can be seen that the constant term of the equation (3) is not small enough to be ignored and also the correlation is fairly low. Therefore an expectancy factor $e$ cannot be derived and applicability of corrected PMV-PPD model for this climatic region still remains to determined. We argue that human response to thermal environment is a very complex phenomenon, continuously changing and governed by many objective and subjective factors, thus it cannot be simply predicted by adding a corrected factor $e$ to the PMV-PPD model. Thus we do not recommend the application of corrected PMV-PPD model in this climatic region.

\subsubsection{Other analyses related to comfort temperature and adaptive mechanisms}

To clarify some other comfort-related issues, 7 statistical significance tests on the correlations of objective parameters and their attributes were done. The test results were reported in Table 4. It's worth noting that a statistically significant test does not confirm a strong correlation or large difference, but only gives a proof of the existing correlation or difference.

Table 4: Results of some statistical significance tests of some parameters and variables' attributes in NV building

\begin{tabular}{|c|c|c|c|c|c|c|}
\hline First variable & $\begin{array}{l}\text { Second } \\
\text { variable }\end{array}$ & $\begin{array}{l}\text { Number of } \\
\text { observations }\end{array}$ & $\begin{array}{l}\text { Item to be } \\
\text { tested }\end{array}$ & $\begin{array}{l}\text { Statistical test } \\
\text { method }\end{array}$ & $\begin{array}{l}\text { Mean or observed } \\
\text { value of the item to } \\
\text { be tested }\end{array}$ & $\begin{array}{l}\text { P- } \\
\text { value* }\end{array}$ \\
\hline $\begin{array}{l}\text { Gender } \\
\text { Male }\end{array}$ & $\begin{array}{l}\text { Gender } \\
\text { Female }\end{array}$ & $\begin{array}{l}\text { Female: } \\
1071 \\
\text { Male: } 912\end{array}$ & $\begin{array}{l}\text { Difference of } \\
\text { mean comfort } \\
\text { temperature }\end{array}$ & $\begin{array}{l}\text { Two } \\
\text { independent } \\
\text { samples T-test }\end{array}$ & $\begin{array}{l}\text { Female: } 27.39^{\circ} \mathrm{C} \\
\text { Male: } 27.24^{\circ} \mathrm{C}\end{array}$ & 0.710 \\
\hline $\begin{array}{l}\text { Operative } \\
\text { temperature }\end{array}$ & $\begin{array}{l}\text { Clothing } \\
\text { insulation }\end{array}$ & 3047 & Correlation & $\begin{array}{l}\text { Simple linear } \\
\text { regression test }\end{array}$ & $\begin{array}{l}\text { Clo }=-0.268 \mathrm{~T}_{\mathrm{o}}+ \\
1.264\left(\mathrm{R}^{2}=0.1321\right)\end{array}$ & 0.000 \\
\hline $\begin{array}{l}\text { Relative } \\
\text { humidity }\end{array}$ & $\begin{array}{l}\text { Subject's } \\
\text { comfort } \\
\text { temperature }\end{array}$ & 3054 & Correlation & $\begin{array}{l}\text { Simple linear } \\
\text { regression test }\end{array}$ & $\begin{array}{l}\mathrm{T}_{\mathrm{comf}}=0.073 \mathrm{RH}+ \\
22.77\left(\mathrm{R}^{2}=0.056\right)\end{array}$ & 0.000 \\
\hline Air velocity & $\begin{array}{l}\text { Subject's } \\
\text { comfort } \\
\text { temperature }\end{array}$ & 2957 & Correlation & $\begin{array}{l}\text { Simple linear } \\
\text { regression test }\end{array}$ & $\begin{array}{l}\mathrm{T}_{\text {comf }}=0.670 \mathrm{~V}_{\mathrm{a}}+ \\
27.666\left(\mathrm{R}^{2}=0.0029\right)\end{array}$ & 0.003 \\
\hline Air velocity & $\begin{array}{l}\text { Operative } \\
\text { temperature }\end{array}$ & 3058 & Correlation & $\begin{array}{l}\text { Simple linear } \\
\text { regression test }\end{array}$ & $\begin{array}{l}\mathrm{V}_{\mathrm{a}}=0.006 \mathrm{~T}_{\mathrm{o}}+0.081 \\
\left(\mathrm{R}^{2}=0.0037\right)\end{array}$ & 0.001 \\
\hline $\begin{array}{l}\text { Time taking } \\
\text { questionnaire: } \\
\text { before } 12: 00\end{array}$ & $\begin{array}{l}\text { Time taking } \\
\text { questionnaire: } \\
\text { after } 12: 00\end{array}$ & $\begin{array}{l}\text { Before: } 416 \\
\text { After: } 1574\end{array}$ & $\begin{array}{l}\text { Difference of } \\
\text { mean comfort } \\
\text { temperature }\end{array}$ & $\begin{array}{l}\text { Two } \\
\text { independent } \\
\text { samples T-test }\end{array}$ & $\begin{array}{l}\text { Before: } 27.26^{\circ} \mathrm{C} \\
\text { After: } 27.40^{\circ} \mathrm{C}\end{array}$ & 0.360 \\
\hline $\begin{array}{l}\text { Subjects' age } \\
\text { over } 25\end{array}$ & $\begin{array}{l}\text { Subjects' age } \\
\text { under } 25\end{array}$ & $\begin{array}{l}\text { Over: } 665 \\
\text { Under: } 1308\end{array}$ & $\begin{array}{l}\text { Difference of } \\
\text { mean comfort } \\
\text { temperature }\end{array}$ & $\begin{array}{l}\text { Two } \\
\text { independent } \\
\text { samples T-test }\end{array}$ & $\begin{array}{l}\text { Over: } 27.62^{\circ} \mathrm{C} \\
\text { Under: } 27.24^{\circ} \mathrm{C}\end{array}$ & 0.004 \\
\hline
\end{tabular}

* The significance threshold is 0.01

From Table 4, it can be seen that male and female subjects almost have the same comfort temperature since the difference was not statistically significant $(\mathrm{P}=0.71>0.01)$. Similarly, subjects' comfort temperature was not significantly different in the morning and afternoon $(\mathrm{P}=$ $0.36>0.01)$ that is quite consistent with the results from earlier studies [35, 36]. This indicates that the same thermal comfort conditions can be applied from the morning to the evening. The analysis of subject's age and comfort temperature give evidence that older subjects tend to prefer slightly warmer environment.

Statistically significant correlations between clothing insulation, air velocity and operative temperature gave evidence of subjects' adaptations. As temperature increases, subjects tend to turn on the fans or to open the windows along with wearing lighter clothes. Among these adaptive actions, changing clothing seems to be more common and more effective $\left(\mathrm{R}^{2}=0.132\right)$. Table 4 also shows statistically significant correlations between air velocity, humidity and 
comfort temperature although these relations are very weak (very low $\mathrm{R}^{2}$ ). This reveals that air velocity and humidity played a minor role in subjects' comfort temperature.

\section{Conclusion}

This paper presents a full description of an adaptive comfort study for South-East Asia. Meta-analysis was done on field observations collected from field surveys conducted around South-East Asia. An adaptive comfort model was generated and applicable to naturally ventilated buildings under hot and humid conditions.

While some studies assumed a minor role of "Griffiths constant" in the establishment of adaptive comfort equation, this study give proof of its crucial role. Consequently, it must be chosen with much care. The adaptive equation obtained from the present study is rather similar to some other standards although the methods used were not identical. The resulted comfort equation is:

\section{$\mathrm{T}_{\text {comf }}=0.341 \mathrm{~T}_{\mathrm{a}, \text { out }}+18.83$}

The study also found that at rather high temperature and humidity, adaptive actions do not seem very effective and the comfort range is, consequently, slightly smaller than that under more favorable conditions.

The statistically significant correlation between temperature and wind velocity as well as clothing insulation gave strong proofs of occupant's adaptation. Under hot and humid conditions, the neutral ambient temperature in NV building is nearly $2{ }^{\circ} \mathrm{C}$ higher than that in AC building. However, the same neutral SET* in these buildings gave some proofs that this deviation mainly came from various behavioral adaptations of occupant. Under favorable conditions, the difference between neutral operative temperature in NV and AC building might become minor, as the case of Guangzhou in mild seasons.

This study carefully examined the relationship between predicted PMV and actual TSV in NV building and did not recommend the application of PMV-PPD model for similar comfort studies, even if this model is adjusted by some corrections.

Since our recorded observations in NV building mainly had the temperature range from 26 ${ }^{\circ} \mathrm{C}$ to $34{ }^{\circ} \mathrm{C}$, the present adaptive comfort model should be enlarged by other surveys in various conditions under $26{ }^{\circ} \mathrm{C}$ or above $34^{\circ} \mathrm{C}$. Such surveys would give more consistent proofs about subject's thermal sensitivity, its relationship to the temperature range and outdoor conditions.

\section{Acknowledgments}

This study was financially supported by the Ministry of Education and Training of Vietnam (Grant No. 624/QĐ-BGDĐT $9^{\text {th }}$ Feb 2010) and partly by Wallonie Bruxelles International (Grant No. DWBH/FP/vtd/V084/2011). This research is completely relied on field survey data from various studies around South-East Asia. We would like to express our greatest appreciation to following professors for their donations of field survey data and useful guides: Nuyk Hien Wong (National University of Singapore); Henry Feriadi (Duta Wacana Christian University); Yufeng Zhang and his survey team (South China University of Technology); Mary Myla Andamon (University of Adelaide); Ibrahim Hussein (Universiti Tenaga Nasional); and other authors in ASHRAE RP-884 database. We greatly thank to Dr. To Mai Xuan Hong (Hochiminh city University of Medicine and Pharmacy) for the support in statistics.

\section{References}

[1] Fanger PO. Thermal comfort. Danish Technical press. Copenhagen; 1970.

[2] ISO. ISO 7730-2005: Ergonomics of the thermal environment - Analytical determination and interpretation of thermal comfort using calculation of the PMV and PPD indices and local thermal comfort criteria. Geneva; 2005.

[3] ASHRAE. ASHRAE standard 55-1992: Thermal Environmental Conditions for Human Occupancy. ASHRAE, Inc. Atlanta; 1992. 
[4] Nicol JF, Humphreys MA. Thermal comfort as part of a selfregulating system. Proceedings of the CIB Symposium on Thermal Comfort, Building Research Establishment. Watford; 1972. [5] ASHRAE. ASHRAE standard 55-2004: Thermal Environmental Conditions for Human Occupancy. ASHRAE, Inc. Atlanta; 2004.

[6] Comité Européen de Normalisation. CEN Standard EN15251: Indoor environmental input parameters for design and assessment of energy performance of buildings - addressing indoor air quality, thermal environment, lighting and acoustics. Brussels; 2007.

[7] McCartney KJ, Nicol JF. Developing an adaptive control algorithm for Europe. Energy and Buildings 2002;34:623-35.

[8] Nicol JF. Adaptive thermal comfort standards in the hot-humid tropics. Energy and Buildings 2004;36:628-37.

[9] Glass GV. Primary, secondary, and meta-analysis of research. Educational Researcher 1976; 5:3-8.

[10] Rosenthal R. The "File Drawer Problem" and the Tolerance for Null Results. Psychological Bulletin 1979;86(3):638-41.

[11] Hunter JE, Schmidt FL. Methods of Meta-Analysis: Correcting Error and Bias in Research Findings. SAGE Publications. California; London; New Delhi; 1990.

[12] de Dear R, Brager G, Cooper D. Final report - ASHRAE Project RP-884: Developing an Adaptive Model of Thermal Comfort and Preference. 1997.

[13] Nicol, J.F. and McCartney, K.J. SCATS: Final Report—Public. Oxford : Oxford Brookes University, 2001.

[14] Humphreys M. Outdoor temperature and comfort indoor. Building research and practice 1978;6(2):92-105.

[15] Wong NH, Feriadi H, Lim PY, Tham KW, Sekhar C, Cheong KW. Thermal comfort evaluation of naturally ventilated public housing in Singapore. Building and Environment 2002;37:1267-77.

[16] Feriadi H, Wong, NH. Thermal comfort for naturally ventilated houses in Indonesia. Energy and Buildings 2004;36:614-26.

[17] Hussein I, Rahman MHA. Field Study on Thermal Comfort in Malaysia. European Journal of Scientific Research 2009;37(1):134-52.

[18] Zhang Y, Wang J, Chen H, Zhang J, Meng Q. Thermal comfort in naturally ventilated buildings in hot-humid area of China. Building and Environment 2010;45:2562-70.

[19] Andamon MM. PhD thesis: Building climatology and thermal comfort - Thermal environment and occupant responses in Philippine office buildings. University of Adelaide. Adelaide; 2005.

[20] ISO. ISO 9920: Ergonomics of the thermal environment - estimation of the thermal insulation and evaporative resistance of a clothing ensemble. Geneva; 1995.

[21] McCullough EA, Wyon DP. Insulation characteristics of winter and summer indoor clothing. ASHRAE Transactions 1983;89(Part 2B):614-33.

[22] McCullough EA, Jones BW, Huck J. A comprehensive data base for estimating clothing insulation. ASHRAE Transactions 1985;91(2):29-47.

[23] Olesen BW. A new and simpler method for estimating the thermal insulation of a clothing ensemble. ASHRAE Transactions 1985;91(2b):478-92.

[24] Olesen BW, Dukes-DuBos FN. International standards for assessing the effect of clothing on heat tolerance and comfort (in Performance of Protective Clothing, eds S. Z. Mansdorf, R. Sager and A. P. Nielson). Philadelphia; 1988.

[25] de Dear RJ. Thermal comfort prediction calculator. Available at http://web.arch.usyd.edu.au [Accessed 12 Nov 2010].

[26] U.S. Department of Energy. Weather data. Available at http://apps1.eere.energy.gov [Accessed 07 Jan 2012]. 
[27] Nicol JF, Humphreys M. Derivation of the adaptive equations for thermal comfort in freerunning buildings in European standard EN15251. Building and Environment 2010;45:11-7. [28] Auliciems A, Szokolay SV. Thermal comfort, PLEA notes no.3 . PLEA conference. Singapore; 2007. ISBN 0867767294.

[29] Nicol JF, Humpheys M. Adaptive thermal comfort and sustainable thermal standards for buildings. Energy and Buildings 2002;34:563 - 72 .

[30] Griffths I. Thermal comfort studies in buildings with passive solar features, field studies. Report of the Commission of the European Community. UK; 1990. ENS35 090.

[31] de Dear R, Brager GS. Developing an adaptive model of thermal comfort and preference. ASHRAE Transactions 1998;104(1a):145-67.

[32] Humphreys M, Nicol JF, Raja IA. Field studies of indoor thermal comfort and the progress of the adaptive approach. Journal of Advances on Building Energy Research 2007;1:55-88. [33] de Dear R, Brager GS. Thermal comfort in naturally ventilated buildings: revisions to ASHRAE Standard 55. Energy and Buildings 2002;34:549-61.

[34] Fanger PO, Tøftum J. Extension of the PMV model to non-air-conditioned buildings in warm climates. Energy and Buildings 2002;34:533-6.

[35] Fanger PO, Højbjerre J, Thomsen JOB. Thermal comfort conditions in the morning and in the evening. Int. J. Biometeor 1974;8(1):16-22.

[36] Nielsen M. Studies on the relation between sensations of comfort, degree of heating and physiological reactions. Boligopvarmningsudvalgets meddelelse nr. 3. København; 1974 (result reported by Fanger PO). 